\title{
Pseudomonas fluorescens and Azospirillum brasilense Increase Yield and Fruit Quality of Tomato Under Field Conditions
}

\author{
María Micaela Pérez-Rodriguez ${ }^{1} \cdot$ Mariela Pontin $^{1,2} \cdot$ Víctor Lipinski $^{2} \cdot$ Rubén Bottini $^{3} \cdot$ Patricia Piccoli $^{1}$. \\ Ana Carmen Cohen ${ }^{1}$ (1)
}

Received: 6 October 2019 / Accepted: 17 March 2020 / Published online: 14 September 2020

(C) Sociedad Chilena de la Ciencia del Suelo 2020

\begin{abstract}
Crop inoculation with plant growth-promoting rhizobacteria (PGPR) is a sustainable alternative to diminish the excessive use of chemical fertilizers in agriculture. However, there is little information about PGPR inoculation effects under field conditions and even less on industrial tomato production. We aimed to study the effects of a sole inoculation at seedling stage with Pseudomonas fluorescens Rt6M10, Azospirillum brasilense Az39, and their combination on growth and yield of two industrial tomato varieties UCO 14 (UCO) and Harris Moran 3861 (HM). We compared these PGPR inoculation treatments with chemically fertilized and nonfertilized (control) seedlings under field conditions. We found that inoculation with Rt6M10, Az39, and their combination increased seedling root dry weight by $62 \%, 41 \%$, and $23 \%$, respectively and shoot dry weight by $29 \%, 23 \%$, and $2 \%$, respectively compared with non-inoculated control, improving tolerance to transplant stress. Inoculation with Rt6M10, Az39, and their combination increased stem diameter by $15 \%, 16 \%$, and $13 \%$, respectively, while Rt6M10 and the combination treatments increased leaf chlorophyll and carotenoid levels compared with non-inoculated plants. Az39 increased fruit number (35\%) and fruit weight (38\%) per plant in HM, whereas in UCO variety, the increase was the highest ( $48 \%$ and $49 \%$, respectively). Seedling inoculation increase fruit firmness and equatorial and polar fruit diameter by $24 \%, 10 \%$, and $12 \%$, respectively in HM and by $21 \%, 14 \%$, and $14 \%$, respectively in UCO. Overall, bio-inoculation with Rt6M10 and/or Az39 was beneficial for tomato seedlings at transplanting and supported fruit yield and quality (total soluble solid content, $\mathrm{pH}$, and titratable acidity) equally or better than chemically fertilized seedlings.
\end{abstract}

Keywords Bio-fertilization · Industrial tomato $\cdot$ Plant growth-promoting rhizobacteria $($ PGPR) $\cdot$ Root inoculation

\section{Introduction}

The world's population is expected to increase by two billion people in the next 30 years, and therefore, a boost in crop

Electronic supplementary material The online version of this article (https://doi.org/10.1007/s42729-020-00233-x) contains supplementary material, which is available to authorized users.

Ana Carmen Cohen

acohen@fca.uncu.edu.ar

1 Instituto de Biología Agrícola de Mendoza - Facultad de Ciencias Agrarias, Consejo Nacional de Investigaciones Científicas y

Técnicas, Universidad Nacional de Cuyo, Almirante Brown 500, (5507) Chacras de Coria, Mendoza, Argentina

2 Estación Experimental Agropecuaria La Consulta - Instituto Nacional de Tecnología Agropecuaria, Ex Ruta 40, Km 96. (5567) La Consulta, San Carlos, Mendoza, Argentina

3 Área de Ciencia y Técnica, Universidad Juan A. Maza, Av. Acceso Este, Lateral Sur 2245, (5529) Guaymallén, Mendoza, Argentina productivity is required to feed the ever-growing population. In order to protect crops from pests and pathogens and increase the global food production, the use of agrochemicals is frequent, since conventional agriculture is mostly dependent on chemical fertilizers and pesticides (Bhardwaj et al. 2014; Damalas and Eleftherohorinos 2011). Nevertheless, this approach promoted the overuse of chemicals in some areas, leading to a degradation of agricultural lands with consequent negative impacts on the environment (Rahman and Zhang 2018).

Despite the high quantity of nitrogen $(\mathrm{N})$ used for crop fertilization, plants are capable to assimilate only $30-40 \%$ of the total quantity applied. The major losses occur through leaching, denitrification, and volatilization of ammonium to the atmosphere (Jewell et al. 2010). Besides, $\mathrm{N}$ excess causes groundwater contamination (Ahmed et al. 2017). After N, phosphorus $(\mathrm{P})$ is the major plant growth-limiting nutrient, since significant amounts of this element in soils are insoluble, and only a small proportion is available to plants (Gyaneshwar 
et al. 2002). Moreover, $P$ fertilization is not efficient because soluble $\mathrm{P}$ is highly reactive with $\mathrm{Ca}, \mathrm{Fe}$, and $\mathrm{Al}$, forming insoluble compounds that precipitate (Gyaneshwar et al. 2002). Besides, excessive fertilization with $P$ produces eutrophication of surface waters.

Considering the above scenario, the use of plant growthpromoting rhizobacteria (PGPR) in agriculture could be a sustainable and environmentally friendly solution for crop fertilization by reducing the negative impact associated with the excessive use of chemical fertilizers (Glick 2014; Ijaz et al. 2019, 2020). PGPR exert a beneficial effect on plant growth through direct and indirect mechanisms. Direct promotion includes enhanced nutrient availability and nutrient use efficiency through $\mathrm{P}$ solubilization, siderophore production, and $\mathrm{N}$ fixation, as well by reducing microbial-produced ethylene with 1-aminocyclopropane-1-carboxylate deaminase, and production of phytohormones (Bottini et al. 2004; Cohen et al. 2015; Glick 2012, 2014; Salomon et al. 2014). Indirect promotion mechanisms include protection of plants against pathogenic agents, acting as biocontrol bacteria due to production of siderophores, antibiotics, and terpenes and induction of systemic resistance (Piccoli and Bottini 2013; Salomon et al. 2014). The principal PGPR used as biofertilizers include species of the genera Azospirillum, Azotobacter, Bacillus, Pseudomonas, Burkholderia, Streptomyces, and Rhizobia (Glick 2012).

Tomato is the second most cultivated horticultural crop worldwide. Argentina occupies the 12th position in the global production ranking, reaching 436.000 tons in 2017-2018, with Cuyo region (central West Argentina) contributing with $77 \%$ to the total production. Mendoza is located in Cuyo region and is one of the main industrial tomato-producing areas. Given that the national demand is not satisfied by the local industry (Argerich and Smith 2018), increasing yields is of great interest. However, increasing tomato industry yields may require large quantities of chemical fertilizers underpinning the negative consequences mentioned above.

There are many reports about of positive effects of PGPR inoculation on yield and quality of fresh tomato varieties under greenhouse conditions (Gravel et al. 2007; Mena-Violante and Olalde-Portugal 2007), but little evaluation has been conducted under field conditions (Bona et al. 2017, 2018; Kokalis-Burelle et al. 2002; Nzanza et al. 2012). Nevertheless, to date, tomato field experiments studying inoculation with microorganisms have been focused mostly on using arbuscular mycorrhizal fungi (AMF) alone, in combination with PGPR (Kokalis-Burelle et al. 2006; Ordookhani et al. 2013), or with formulations of several PGPR (Bona et al. 2017; Kokalis-Burelle et al. 2006). One of the major challenges in this area of research is the correct application of bacterial inoculants in an open field for sustainable nutrient management (Bhardwaj et al. 2014). However, there are no reports concerning the effects of PGPR on industrial tomato varieties. Therefore, it is necessary to perform field experiments with PGPR in order to increase crop yields while reducing the negative environmental impact of chemical fertilization. Nevertheless, the proper PGPR strain needs to be selected in each PGPR soil-crop system, and the mode of inoculation must be optimized to maximize the promoting effects (Ruzzi and Aroca 2015). Thus, the aim of this study was to evaluate the effect of a single root inoculation at the seedling stage with Pseudomonas fluorescens Rt6M10, Azospirillum brasilense Az39, and the combination of both on yield and fruit quality of two industry tomato varieties in a field trial under a reduced fertilization regime.

\section{Materials and Methods}

\subsection{Bacterial Cultures}

Two bacterial strains and their combination were used to inoculate tomato plants. Pseudomonas fluorescens Rt6M10 (Rt6M10) has been previously isolated from the roots of Vitis vinifera (GenBank accession number KF717080) and was described in Salomon et al. (2014), while Azospirillum brasilense Az39 (Az39) was provided by Alejandro Perticari (Agriculture Collection Laboratory of IMYZA-INTA Castelar, Argentina). Both species fix N; solubilize tricalcium phosphate; produce siderophores and phytohormones, such as indole-3-acetic acid, abscisic acid, and gibberellins (Bottini et al. 2004; García et al. 2017; Perrig et al. 2007; Salomon et al. 2014). One colony of Rt6M10 or Az39 was pre-cultured on Luria Broth Base (Miller's LB Broth Base, Invitrogen, Buenos Aires, Argentina) liquid medium in an orbital shaker (Boeco PSU-10i, Hamburg, Germany) at $32{ }^{\circ} \mathrm{C}$ and $120 \mathrm{rpm}$ until reaching a concentration of $10^{8}$ colony forming units (CFU) $\mathrm{mL}^{-1}$. Each bacterium was harvested by centrifugation at $8000 \mathrm{~g}$ for $10 \mathrm{~min}$ at $4{ }^{\circ} \mathrm{C}$, and the pellets were washed with sterile phosphate-buffered saline (PBS) (Cohen et al. 2015). After centrifugation, cultures were diluted to a concentration of $10^{7} \mathrm{CFU} \mathrm{mL}{ }^{-1}$ for $\mathrm{Az} 39$ or $10^{6} \mathrm{CFU} \mathrm{mL}^{-1}$ for Rt6M10 for further inoculation. These inoculum sizes were selected in previous experiments as being the most effective in seedling growth promotion.

\subsection{Plant Materials, Treatments, and Greenhouse Growth Conditions}

Two industrial varieties of tomato (Lycopersicon esculentum L.), UCO 14 (UCO) and Harris Moran 3861 (HM), were used in this study. HM is a commercial hybrid, highlighted for its productivity and quality, while UCO is a promising new variety in terms of yield and quality (especially considering that it is an open-pollinated cultivar) released by La Consulta Experimental Station, INTA, Argentina. Seeds were surface 
disinfected with $2 \%$ sodium hypochlorite for $5 \mathrm{~min}$, followed by washes with sterile water according to Cohen et al. 2009. For germination, tomato seeds were placed in seedbeds containing three parts of substrate Kekkilä DSM 1 W (Kekkilä professional, Vantaa, Finland) and one part of perlite No. 4. The substrate contained $70 \%$ brown and 30\% dark Sphagnum fuscum dominant peat, $\mathrm{N}-\mathrm{P}_{2} \mathrm{O}_{5}-\mathrm{K}_{2} \mathrm{O}$ 15-12-29, and microelements $0.6 \mathrm{~kg} \mathrm{~m}^{-3}$, with $\mathrm{pH} 5.9$ and electrical conductivity (EC) of $0.2 \mathrm{dS} \mathrm{m}^{-1}$. The seedbeds were placed in a greenhouse at $22 \pm 2{ }^{\circ} \mathrm{C}$ and watered every 2 days. When the seedlings had two fully expanded leaves, the following treatments were applied: 1) control: 1-mL PBS; 2) fertilizer: 1-mL solution of 7-g L ${ }^{-1}$ Hakaphos® Base 18:18:18 (COMPO, Spain), a completely water soluble fertilizer for fruit and vegetable crops, free of chlorine and urea with EDTA-chelated trace elements; 3) Az39: 1-mL PBS with $10^{7} \mathrm{CFU} \mathrm{mL}^{-1}$; 4) Rt6M10: 1-mL PBS containing $10^{6} \mathrm{CFU} \mathrm{mL}^{-1}$; 5) combination: 1-mL PBS containing $10^{7} \mathrm{CFU} \mathrm{mL}^{-1}$ of $\mathrm{Az} 39+$ $10^{6} \mathrm{CFU} \mathrm{mL}{ }^{-1}$ Rt6M10. All treatments were applied on the soil surface. The seedlings were watered with tap water to keep the soil water status at $90 \%$ field capacity. After 3 weeks, the seedlings were transplanted to field conditions previous rustication. At this moment, 12 plants from each treatment were also selected to assess shoot and root dry weight (SDW and RDW, respectively).

\subsection{Field Site}

The experiments were conducted between September 25th and March 10th in an experimental field located at INTA La Consulta (latitude $33^{\circ} 42^{\prime} \mathrm{S}$, longitude $69^{\circ} 04^{\prime} \mathrm{W}$, altitude 947 m a.s.1.), Mendoza, Argentina. Daily data on mean temperature, relative humidity, and precipitation were taken from the weather station of INTA La Consulta (electronic supplementary material 1). The soil was classified as fine sandy loam, typic Torrifluvent, La Consulta series (Soil Survey Staff 2014). The detailed physical/chemical soil parameters are presented in Table 1.The $\mathrm{N}$ content (Kjeldahl) is considered medium, while the contents of $\mathrm{P}$ (extracted with bubbling with $\mathrm{CO}_{2}$ in soil water ratio 1:10) and $\mathrm{K}$ (exchangeable in ammonium acetate $\mathrm{pH} 7$ ) were considered very high. The levels of N-P-K in soil were evaluated in the different phenological phases of the tomato plants.

\subsection{Sowing and Crop Management}

Two field experiments were carried out in two consecutive years (2016-2017 and 2017-2018) with an area about $475 \mathrm{~m}^{2}$. However, because the magnitude of responses was similar in both years of the experiment, the results of the 2016-2017 cropping year are presented in this work. Plants were arranged in rows of $52.8 \mathrm{~m}$. Three rows were used for the different treatments. Thirteen plants by treatment were
Table 1 Physical/chemical soil properties of the experimental field

\begin{tabular}{ll}
\hline Determinant & Value \\
\hline Texture class & Sandy loam \\
$\mathrm{pH}$ & 7.93 \\
Electrical conductivity $\left(\mathrm{dS} \mathrm{m}{ }^{-1}\right)$ & 0.93 \\
Saturation percentage $(\%)$ & 28.75 \\
Soil organic matter $(\%)$ & 1.2 \\
Total nitrogen $\left(\mathrm{mg} \mathrm{kg}^{-1}\right)$ & 600 \\
Available phosphorous $\left(\mathrm{mg} \mathrm{kg}^{-1}\right)$ & 10.2 \\
Extractable potassium $\left(\mathrm{mg} \mathrm{kg}^{-1}\right)$ & 421 \\
\hline
\end{tabular}

distributed every $33 \mathrm{~cm}$ in each row, and the distance between the rows was $1.5 \mathrm{~m}$, reaching a plant density of 20,202 plants $\mathrm{ha}^{-1}$. Each treatment was arranged in a completely randomized design and was separated by a set of three non-inoculated plants used as spacers. Plants were watered by using a drip irrigation system. Measurements were recorded at the reproductive stage. Fruit quality was analyzed at harvest time.

\subsection{Sampling and Plant Parameter Determinations}

Ninety days after transplanting, stem diameter, photochemical efficiency of photosystem II (Fv/Fm), chlorophyll relative amount, and photosynthetic pigment levels were evaluated. In each plant, the diameter of the main stem was measured with a digital micrometer at $5 \mathrm{~cm}$ from the plant base. Chlorophyll relative content was determined using a portable chlorophyll meter (SPAD-502, Konica Minolta Sensing, Osaka, Japan). The Fv/Fm was calculated with a fluorometer (Hansatech Instruments LTD, King's Lynn, Norfolk, UK). Pigment determinations were done spectrophotometrically as described in Cohen et al. (2015). Total chlorophyll (Chl; Chl $a+\mathrm{Chl} b$ ) and carotenoid levels were measured from $1-\mathrm{cm}^{2}$ leaf area, and total phenolic compounds $\left(\mathrm{TPC}_{\mathrm{S}}\right)$ and anthocyanin levels were determined using 10-mg dry weight (DW) leaf samples (Cohen et al. 2015). The leaves N (modified Kjeldahl method, Nelson and Sommers 1973) and P content (Jackson 1973) were also analyzed. At harvest time (115 days after transplanting), the number and the fresh weight (FW) of fruits per plant were assessed. Thirty plants of each treatment were used (10 plants in each treatment by each row). In addition, of the total fruits harvested by treatment, 30 fruits were randomly chosen, and equatorial and polar diameter was measured.

\subsection{Qualitative Analyses of Fruits}

For the biochemical analysis, 4 fruits of the total of fruits harvested per plant (10 plants of each treatment per row) were pooled and homogenized. Therefore, each analysis consisted of 30 replicates. The fruit total soluble solid content, $\mathrm{pH}$ value, 
and titratable acids were measured. Fruit total soluble solid content was measured with a hand refractometer Poket PAL1 (ATAGO, Japan), in which two drops of filtered fruit juice were placed on the prism for reading. Titratable acidity was determined on 5-g fruit pulp homogenized using a blender (Phillips, Argentine) with 50-mL distilled water. The extract was filtered, $10-\mathrm{mL}$ aliquots were taken, and $\mathrm{NaOH} 0.01 \mathrm{~N}$ were added until neutralization. Titratable acidity percentage was expressed as percentage of citric acid. The firmness of fruits with skins was indirectly determined with a texture meter (Fruit Firmness Tester FT 327 Facchini SRL, Italy), with a plunger of $8-\mathrm{mm}$ diameter.

\subsection{Statistical Analysis}

All statistical analyses were performed with the InfoStat software (InfoStat version 2016v. Grupo InfoStat, Argentina). One-way ANOVA and Fisher's least significant difference (LSD) test was used to evaluate the effect of inoculation or fertilization treatments $(P \leq 0.05)$ on seedlings and to analyze pigment, $\mathrm{N}$, and $\mathrm{P}$ levels on plants. To assess differences between treatments for parameters (stem diameter, Fv/Fm, chlorophyll relative amount, fruit $\mathrm{FW}$ per plant, equatorial and polar diameter, fruit total soluble solid content, $\mathrm{pH}$ value, titratable acids, and firmness), data were analyzed by fitting linear mixed-effects models (GLM) considering variety (V), inoculation $(\mathrm{Ba})$, and their interaction as fixed factors $(\alpha=$ 0.05). Post-hoc comparison of means was done with Fisher's multiple comparisons test. The fruit number per plant was analyzed by fitting a generalized linear mixed model (GLMM) with the Poisson distribution. Principal component analyses (PCA) are presented as Biplot graphs.

\section{Results}

\subsection{Effects of PGPR Treatments on Seedling Growth}

The different bacterial suspensions (Az39, Rt6M10, and Az39 + Rt6M10) improved growth parameters in tomato seedlings (UCO and HM) grown in seedbed conditions with respect to the untreated individuals (control). The inoculation treatment equaled or surpassed those fertilized at the seedling stage (Fig. 1a). Both strains, Az39 and Rt6M10, were capable to colonize soil and roots of tomato seedlings in each treatment. Figure 1 shows data for HM variety, but similar results were obtained with UCO (electronic supplementary material 2).

Root DW was $62 \%$ higher in Rt6M10 as compared with that in control. RDW in Az39 and in the combination treatment were also higher than control and equaled those of chemically fertilized seedlings (Fig. 1b). Similar results were obtained in respect with SDW, where Rt6M10 and Az39 increased this variable by $29 \%$ and $23 \%$, but only Rt6M10

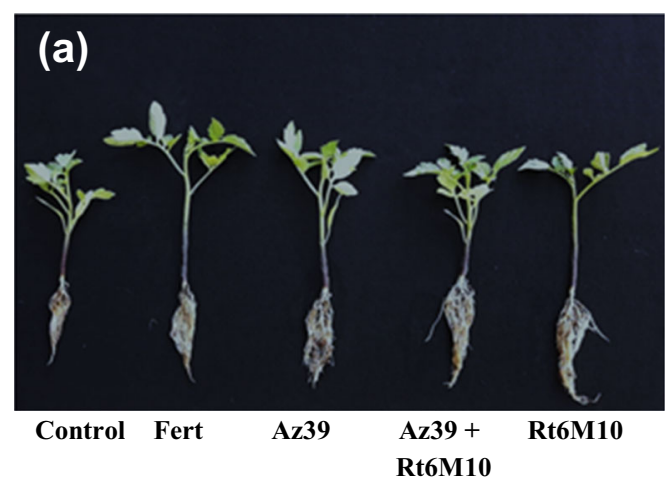

(b)
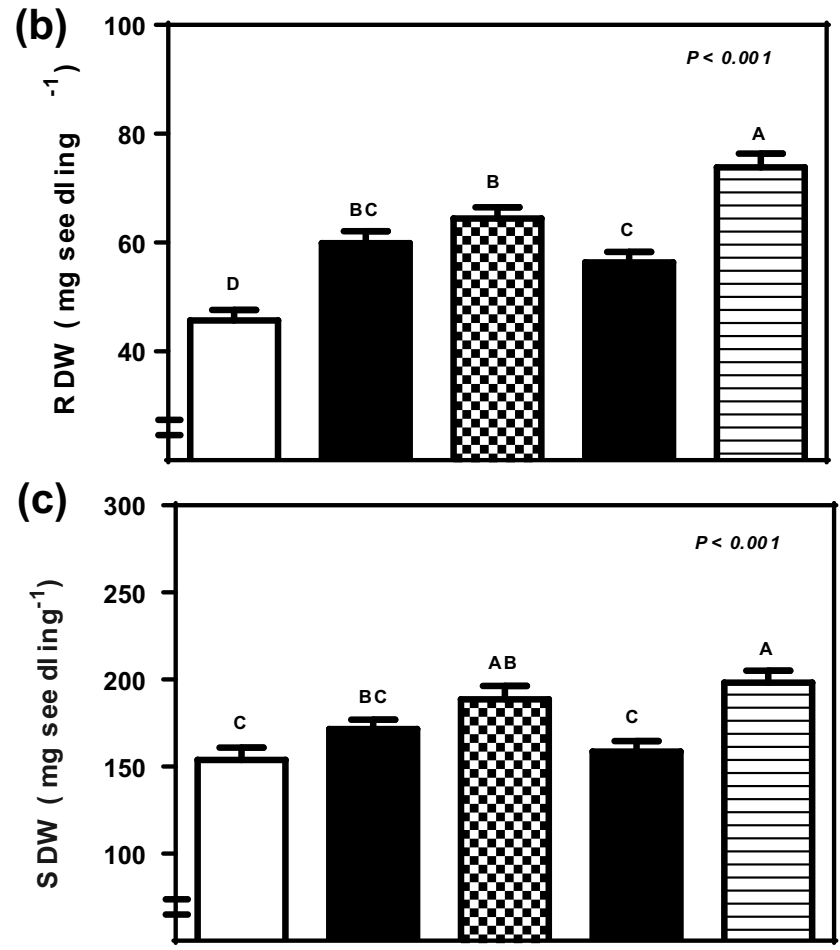

(d)

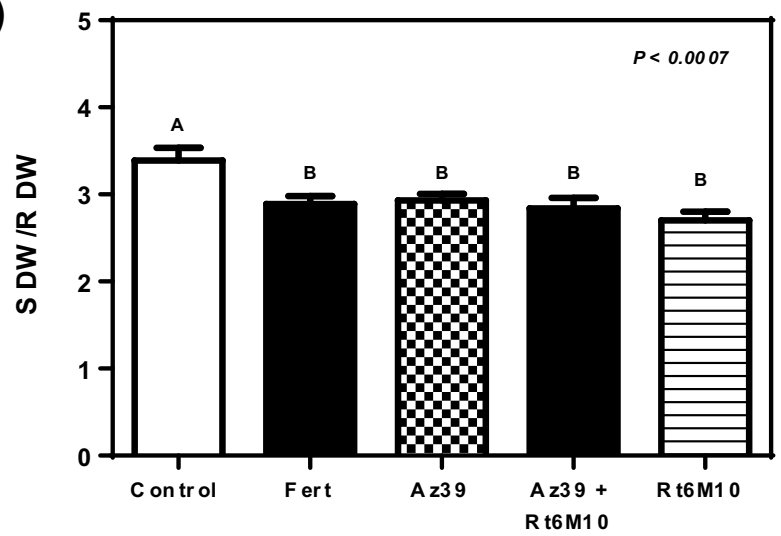

Fig. 1 a Photograph of non-inoculated 50-day-old tomato plants variety HM 3861 (HM) (control), fertilized and inoculated with Azospirillum brasilense Az39 (Az39), combination (Az39 + Rt6M10), or Pseudomonas fluorescens Rt6M10 (Rt6M10). b Root dry weight (RDW, mg). c Shoot dry weight (SDW, mg). d SDW/RDW ratio. Values are means $\pm \mathrm{SE}(n=12)$. Different letters indicate significant differences $(P \leq 0.05)$ 
differentiated from SDW of the chemically fertilized seedlings $(12 \%)$. The combination treatment did not differ with control (Fig. 1c). The ratio between SDW/RDW in control was greater than that for the other treatments (Fig. 1d).

\subsection{Field Study: Plant Parameters in the Reproductive Stage}

The stem diameter in UCO variety was bigger than HM. The inoculation with Az39, combination, or Rt6M10 significantly increased the stem diameter compared with non-inoculated plants and equaled the fertilized treatment in both varieties (Table 2). The effects of bacterial treatments were similar in both varieties, and there was no interaction between variety and inoculation treatment (Table 2). Fv/Fm was similar between control and inoculated treatments (Az39 and/or Rt6M10). However, the fertilization of seedlings decreased $\mathrm{Fv} / \mathrm{Fm}$ in the two varieties (Table 2). SPAD index, indicative of chlorophyll relative content, increased with respect to control and presented intermediate values for the plants fertilized at the seedling stage (Table 2).

Also, total chlorophyll, carotenoid, photoprotective compounds, anthocyanin, $\mathrm{N}$, and $\mathrm{P}$ levels in leaves of $\mathrm{HM}$ (Table 3) and UCO (electronic supplementary material 3) were measured. Rt6M10 and the combination treatment increased total chlorophyll levels compared with control, which showed similar levels to the fertilized treatment. The carotenoid levels were increased by Rt6M10, the combination treatment, and the fertilized treatment with respect to the control. Total photoprotective compounds were increased only by Rt6M10. Treatments did not affect anthocyanin levels in leaves. There was no significant difference between control, fertilized, and Az39 or Rt6M10 treatments, but the combination treatment decreased the P content. The control, Az39, and Rt6M10 treatments were statistically similar in N content, but fertilized and combination treatments showed the highest $\mathrm{N}$ content.

\subsection{Fruit Yield}

Irrespective of treatment, $\mathrm{HM}$ had more ripe fruits than $\mathrm{UCO}$, although differences disappeared when fruit FW was considered (Fig. 2 a and b). For both cultivars, fertilization of seedlings and inoculated plants rendered more ripe fruits with a higher yield than control (Fig. 2a). Plants inoculated with Az39 showed the maximum increase in the number and FW of fruits per plant (35\% and $38 \%$ in HM, whereas $48 \%$ and $49 \%$ in UCO, respectively) in comparison with control. The fruit FW was the lowest in UCO. Seedling chemical fertilization was more effective in UCO variety without differences with inoculation. In the two varieties, the inoculation treatment increased fruit FW (Fig. 2b). The tomato fruit shape was different; HM had lower equatorial diameter than UCO, while UCO had lower polar diameter than HM (Table 4). Notwithstanding, both the equatorial diameter and the polar diameter were increased by seedling fertilization (between 4 and $5 \%$ in $\mathrm{HM}$ and 9 and $10 \%$ in UCO, respectively) and inoculations (between 10 and $12 \%$ in $\mathrm{HM}$ and $14 \%$ in UCO, respectively), with the effect of the latter being greater in the two varieties assessed in comparison with control (Table 4).

\subsection{Qualitative Analyses of Fruits}

Firmness of the fruit was similar in both varieties and was equally increased by seedling chemical fertilization and inoculation combination, but augmented even more in those
Table 2 Stem diameter, maximum quantum efficiency of PSII (Fv/Fm), and spad index from tomato plants (HM and UCO varieties) cultivated in a field trial. Treatments: noninoculated plants (control), fertilized at seedling stage, and inoculated with Azospirillum brasilense Az39 (Az39), combination (Az39 + Rt6M10), or Pseudomonas fluorescens Rt6M10 (Rt6M10)

\begin{tabular}{lllll}
\hline Variety & Treatments & Stem diameter $(\mathrm{mm})$ & Fv/Fm & Spad index \\
\hline HM & Control & $13.49 \pm 0.29^{\mathrm{e}}$ & $0.80 \pm 0.01^{\mathrm{ab}}$ & $55.56 \pm 0.55^{\mathrm{d}}$ \\
& Fertilized & $15.83 \pm 0.31^{\mathrm{abc}}$ & $0.76 \pm 0.01^{\mathrm{c}}$ & $57.00 \pm 0.96^{\mathrm{bcd}}$ \\
& Az39 & $16.07 \pm 0.32^{\mathrm{ab}}$ & $0.80 \pm 0.01^{\mathrm{ab}}$ & $58.30 \pm 1.03^{\mathrm{abc}}$ \\
& Combination & $15.26 \pm 0.22^{\mathrm{c}}$ & $0.80 \pm 0.01^{\mathrm{ab}}$ & $58.53 \pm 0.82^{\mathrm{abc}}$ \\
& Rt6M10 & $15.52 \pm 0.22^{\mathrm{bc}}$ & $0.78 \pm 0.01^{\mathrm{b}}$ & $58.21 \pm 1.07^{\mathrm{abc}}$ \\
$\mathrm{UCO}$ & Control & $14.37 \pm 0.25^{\mathrm{d}}$ & $0.80 \pm 0.01^{\mathrm{ab}}$ & $56.13 \pm 0.74^{\mathrm{cd}}$ \\
& Fertilized & $16.39 \pm 0.22^{\mathrm{ab}}$ & $0.75 \pm 0.01^{\mathrm{c}}$ & $57.77 \pm 0.74^{\mathrm{abcd}}$ \\
& Az39 & $16.17 \pm 0.25^{\mathrm{ab}}$ & $0.81 \pm 0.01^{\mathrm{a}}$ & $59.83 \pm 0.86^{\mathrm{a}}$ \\
& Combination & $15.97 \pm 0.32^{\mathrm{abc}}$ & $0.79 \pm 0.01^{\mathrm{b}}$ & $58.33 \pm 0.91^{\mathrm{abc}}$ \\
& Rt6M10 & $16.42 \pm 0.23^{\mathrm{a}}$ & $0.81 \pm 0.01^{\mathrm{ab}}$ & $58.58 \pm 0.87^{\mathrm{ab}}$ \\
& $P(\mathrm{~V})$ & 0.0003 & 0.8043 & 0.2720 \\
& $P(\mathrm{Ba})$ & $\leq 0.0001$ & $\leq 0.0001$ & 0.0023 \\
& $P(\mathrm{~V} \times$ Ba) & 0.5979 & 0.1708 & 0.9048 \\
\hline
\end{tabular}

$P(\mathrm{~V})$, effect of $\mathrm{HM}$ and $\mathrm{UCO}$ varieties; $P(\mathrm{Ba})$, inoculation and fertilized treatment; $P(\mathrm{~V} \times \mathrm{Ba})$, interaction effect. Values are means \pm SE $(n=30)$. Statistical comparisons are among treatments within a single column. The different letters indicate significant differences using Fisher's LSD test at $P<0.05$ 
Table 3 Levels of total chlorophyll, carotenoids, total phenolic compounds (TPC), anthocyanins, and P and N content measured in tomato plants HM. Treatments: non-inoculated plants (control), fertilized at seedling stage, and inoculated with Az39, Rt6M10, and combination (Az39 + Rt6M10)

\begin{tabular}{|c|c|c|c|c|c|c|}
\hline Treatments & $\begin{array}{l}\mathrm{Chl}\left(\mu \mathrm{g} \mathrm{cm}^{-2}\right. \\
\text { leaf })\end{array}$ & $\begin{array}{l}\text { Carotenoids }\left(\mu \mathrm{g} \mathrm{cm}^{-2}\right. \\
\text { leaf) }\end{array}$ & $\begin{array}{l}\mathrm{TPCs}\left(\mathrm{OD}_{305} \mathrm{mg}\right. \\
\text { leaf })\end{array}$ & $\begin{array}{l}\text { Anthocyanins }\left(\mathrm{OD}_{546} \mathrm{mg}\right. \\
\text { leaf) }\end{array}$ & $\begin{array}{l}\mathrm{P} \text { content ( } \mathrm{mg} \mathrm{g}^{-1} \\
\text { leaf) }\end{array}$ & $\begin{array}{l}\mathrm{N} \text { content ( } \mathrm{mg} \mathrm{g}^{-1} \\
\text { leaf) }\end{array}$ \\
\hline Control & $9.51 \pm 1.21^{\mathrm{b}}$ & $1.50 \pm 0.12^{\mathrm{d}}$ & $0.33 \pm 0.06^{\mathrm{b}}$ & $0.04 \pm 0.010^{\mathrm{a}}$ & $2.59 \pm 0.14^{\mathrm{a}}$ & $40.74 \pm 0.35^{\mathrm{ab}}$ \\
\hline Fertilized & $10.81 \pm 2.04^{\mathrm{ab}}$ & $1.93 \pm 0.26^{\mathrm{a}}$ & $0.33 \pm 0.04^{b}$ & $0.04 \pm 0.047^{\mathrm{a}}$ & $2.34 \pm 0.04^{\mathrm{a}}$ & $43.23 \pm 0.40^{\mathrm{a}}$ \\
\hline Az39 & $9.66 \pm 1.75^{\mathrm{b}}$ & $1.57 \pm 0.38^{\mathrm{cd}}$ & $0.31 \pm 0.03^{\mathrm{b}}$ & $0.04 \pm 0.010^{\mathrm{a}}$ & $2.28 \pm 0.05^{\mathrm{a}}$ & $37.77 \pm 0.21^{b}$ \\
\hline Combination & $11.12 \pm 1.15^{\mathrm{a}}$ & $1.72 \pm 0.14^{\mathrm{bc}}$ & $0.31 \pm 0.05^{\mathrm{b}}$ & $0.03 \pm 0.001^{\mathrm{a}}$ & $2.01 \pm 0.03^{b}$ & $43.57 \pm 2.23^{\mathrm{a}}$ \\
\hline \multirow[t]{2}{*}{ Rt6M10 } & $11.56 \pm 1.78^{\mathrm{a}}$ & $1.87 \pm 0.24^{\mathrm{ab}}$ & $0.38 \pm 0.03^{\mathrm{a}}$ & $0.03 \pm 0.010^{\mathrm{a}}$ & $2.49 \pm 0.19^{\mathrm{a}}$ & $39.08 \pm 0.11^{b}$ \\
\hline & $P=0.0093$ & $P=0.0002$ & $P=0.0028$ & $P=0.1236$ & $P=0.0396$ & $P=0.0096$ \\
\hline
\end{tabular}

Values are means $\pm \mathrm{SE}(n=12$ and $n=3$ for $\mathrm{P}$ content and $\mathrm{N}$ content). Statistical comparisons are among treatments within a single column. The different letters indicate significant differences using Fisher's LSD test at $P<0.05$

inoculated with bacteria (Az39 or Rt6M10) (Table 4). HM variety presented fruits with higher soluble solid $(5.76 \pm$ $0.42)$ content than UCO $(5.16 \pm 0.43)$. The ${ }^{\circ}$ Brix was not affected either by inoculation or fertilization in HM variety, without any interaction between variety and inoculation treatments. Considering UCO variety, only the fruits produced by plants inoculated with Rt6M10 presented a higher total soluble solid content compared with control and the chemically fertilized treatment (Table 4). $\mathrm{pH}$ of fruits was not influenced by inoculation, although it presented higher values in UCO than in HM variety. There was no interaction between variety and inoculation. In HM, there were $\mathrm{pH}$ differences in Rt6M10 and combination compared with control (Table 4). Titratable acidity was affected by inoculation, variety, and their interaction (Table 4). In the fruits of HM, the major values of titrable acidity were observed in control, followed by the chemically fertilized treatment. The inoculation with Az39 or Rt6M10 induced a reduction of this parameter as compared with control and the chemically fertilized seedlings. However, Az39+ Rt6M10 presented a lower value compared with control but did not differ with that of the chemically fertilized seedlings. In fruits of UCO variety, control presented the higher values as compared with the other treatments. Only the inoculation

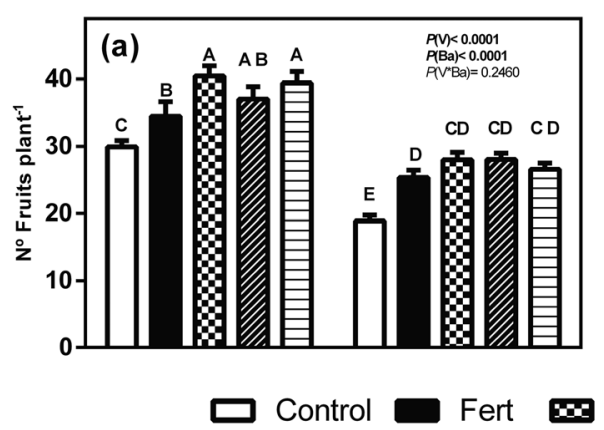

Fig. 2 a Number and b fresh weight (FW) of fruits per plant from tomato plants of varieties HM and UCO cultivated in a field trial. Treatments: non-inoculated plants (control), fertilized at seedling stage, and inoculated with Azospirillum brasilense Az39 (Az39), combination (Az39 + with Az39 induced a significant reduction of titrable acidity compared with the chemically fertilized seedlings (Table 4).

The PCA showed that inoculation treatments in both varieties were different from the control with $72.4 \%$ (HM) and $71.7 \%$ (UCO) of the variability explained by stem diameter, Fv/Fm, SPAD index, number of fruits per plant, fruit FW per plant, fruit firmness, equatorial and polar diameter, $\mathrm{pH}$, and fruit total soluble solids (Fig. $3 \mathrm{a}$ and b).

\section{Discussion}

Our findings demonstrated that a single inoculation dose of PGPR of tomato seedlings cultivated in the greenhouse increased RDW over SDW. By consequence, when these "more rooted" seedlings were transplanted, an overall augmentation in plant growth and yield was achieved. That is, the enhanced plant growth may be explained by a better root development that gives potential for improved water and nutrient uptake. The inoculation with Rt6M10 or Az39 increased RDW and SDW of seedlings when used alone, but the combination did not differ from control in SDW. Walker et al. (2012) suggested that the effect of bacteria applied in combination can

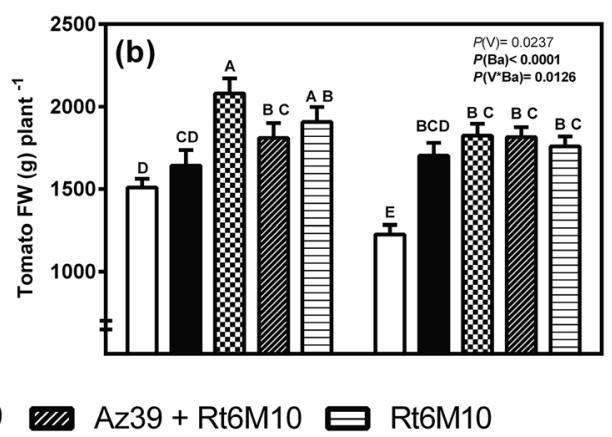

Rt6M10), or Pseudomonas fluorescens Rt6M10 (Rt6M10). P(V), effect of HM and UCO varieties; $P(\mathrm{Ba})$, inoculation and fertilized treatment; $P(\mathrm{~V} \times \mathrm{Ba})$, interaction effect. Values are means $\pm \mathrm{SE}(n=30)$. Different letters indicate significant differences $(P \leq 0.05)$ 
Table 4 Equatorial and polar diameters, fruit firmness, total soluble solid content ( $\left.{ }^{\circ} \mathrm{Brix}\right), \mathrm{pH}$, and titratable acidity (\% citric acid) of fruits from tomato plants (HM and UCO varieties) cultivated in a field trial.
Treatments: non-inoculated plants (control), fertilized at seedling stage, and inoculated with Az39, Rt6M10, and combination (Az39 + Rt6M10)

\begin{tabular}{|c|c|c|c|c|c|c|c|}
\hline Variety & Treatments & Equatorial diameter $(\mathrm{cm})$ & Polar diameter $(\mathrm{cm})$ & Firmness of fruits (lbf) & ${ }^{\circ}$ Brix & $\mathrm{pH}$ & Titratable acidity $(\%)$ \\
\hline \multirow[t]{5}{*}{$\mathrm{HM}$} & Control & $37.34 \pm 0.38^{\mathrm{f}}$ & $69.16 \pm 0.58^{d}$ & $3.76 \pm 0.08^{\mathrm{ef}}$ & $5.76 \pm 0.08^{\mathrm{a}}$ & $4.46 \pm 0.02^{\mathrm{d}}$ & $0.42 \pm 0.01^{\mathrm{a}}$ \\
\hline & Fertilized & $38.97 \pm 0.37^{\mathrm{e}}$ & $72.65 \pm 0.52^{\mathrm{c}}$ & $4.26 \pm 0.10^{\mathrm{bc}}$ & $5.75 \pm 0.06^{\mathrm{a}}$ & $4.47 \pm 0.03^{\mathrm{cd}}$ & $0.40 \pm 0.01^{\mathrm{b}}$ \\
\hline & Az39 & $41.47 \pm 0.43^{\mathrm{d}}$ & $78.61 \pm 0.77^{\mathrm{a}}$ & $4.77 \pm 0.11^{\mathrm{a}}$ & $5.76 \pm 0.10^{\mathrm{a}}$ & $4.51 \pm 0.02^{\mathrm{bcd}}$ & $0.34 \pm 0.01^{\mathrm{de}}$ \\
\hline & Combination & $41.27 \pm 0.31^{\mathrm{d}}$ & $76.62 \pm 0.83^{\mathrm{b}}$ & $4.53 \pm 0.14^{\mathrm{ab}}$ & $5.72 \pm 0.07^{\mathrm{a}}$ & $4.53 \pm 0.02^{\mathrm{abc}}$ & $0.37 \pm 0.01^{\mathrm{bc}}$ \\
\hline & Rt6M10 & $40.95 \pm 0.36^{\mathrm{d}}$ & $77.50 \pm 0.84^{\mathrm{ab}}$ & $4.71 \pm 0.12^{\mathrm{a}}$ & $5.80 \pm 0.07^{\mathrm{a}}$ & $4.53 \pm 0.03^{\mathrm{abc}}$ & $0.34 \pm 0.01^{\text {def }}$ \\
\hline \multirow[t]{8}{*}{$\mathrm{UCO}$} & Control & $44.70 \pm 0.33^{\mathrm{c}}$ & $59.37 \pm 0.34^{\mathrm{f}}$ & $3.57 \pm 0.10^{f}$ & $5.08 \pm 0.09^{\mathrm{cd}}$ & $4.54 \pm 0.02^{\mathrm{ab}}$ & $0.36 \pm 0.01^{\mathrm{cd}}$ \\
\hline & Fertilized & $48.66 \pm 0.42^{\mathrm{b}}$ & $65.33 \pm 0.53^{\mathrm{e}}$ & $3.90 \pm 0.08^{\mathrm{de}}$ & $4.95 \pm 0.07^{\mathrm{d}}$ & $4.58 \pm 0.01^{\mathrm{a}}$ & $0.32 \pm 0.01^{\mathrm{ef}}$ \\
\hline & Az39 & $51.22 \pm 0.34^{\mathrm{a}}$ & $67.62 \pm 0.65^{\mathrm{d}}$ & $4.56 \pm 0.12^{\mathrm{ab}}$ & $5.15 \pm 0.08^{\mathrm{cd}}$ & $4.58 \pm 0.02^{\mathrm{a}}$ & $0.28 \pm 0.01^{\mathrm{g}}$ \\
\hline & Combination & $51.42 \pm 0.27^{\mathrm{a}}$ & $67.71 \pm 0.48^{\mathrm{d}}$ & $4.19 \pm 0.11^{\mathrm{cd}}$ & $5.25 \pm 0.07^{\mathrm{bc}}$ & $4.53 \pm 0.02^{\mathrm{a}}$ & $0.32 \pm 0.01^{\mathrm{ef}}$ \\
\hline & Rt6M10 & $50.61 \pm 0.36^{\mathrm{a}}$ & $68.09 \pm 0.59^{d}$ & $4.25 \pm 0.13^{\mathrm{bc}}$ & $5.39 \pm 0.07^{\mathrm{b}}$ & $4.58 \pm 0.02^{\mathrm{a}}$ & $0.32 \pm 0.01^{\mathrm{f}}$ \\
\hline & $P(\mathrm{~V})$ & $\leq 0.0001$ & $\leq 0.0001$ & $\leq 0.0010$ & $\leq 0.0001$ & $\leq 0.0001$ & $\leq 0.0001$ \\
\hline & $P(\mathrm{Ba})$ & $\leq 0.0001$ & $\leq 0.0001$ & $\leq 0.0001$ & 0.0250 & 0.0918 & $\leq 0.0001$ \\
\hline & $P(\mathrm{~V} \times \mathrm{Ba})$ & 0.0009 & 0.0646 & 0.7552 & 0.0754 & 0.6348 & 0.0346 \\
\hline
\end{tabular}

$P(\mathrm{~V})$, effect of HM and UCO varieties; $P(\mathrm{Ba})$, inoculation and fertilized treatment; $P(\mathrm{~V} \times \mathrm{Ba})$, interaction effect. Values are means $\pm \mathrm{SE}(n=30)$. Statistical comparisons are among treatments within a single column. The different letters indicate significant differences using Fisher's LSD test at $P<0.05$

${ }^{a}$ Expressed as citric acid equivalent

Fig. 3 Biplot display of principal component analysis (PCA) of the parameters analyzed in tomato plants of varieties a HM and $\mathbf{b}$ UCO. Treatments (घ): noninoculated (control), fertilized at seedling stage, and inoculated with Azospirillum brasilense Az39 (Az39), combination (Az39 + Rt6M10), or Pseudomonas fluorescens Rt6M10 (Rt6M10). Factors (o): stem diameter, Fv/ Fm, spad index, number fruits per plant, tomato $\mathrm{FW}$ per plant, fruit firmness, equatorial and polar diameter tomato, $\mathrm{pH}$, titrable acidity, and total soluble solid content ( ${ }^{\circ}$ Brix)
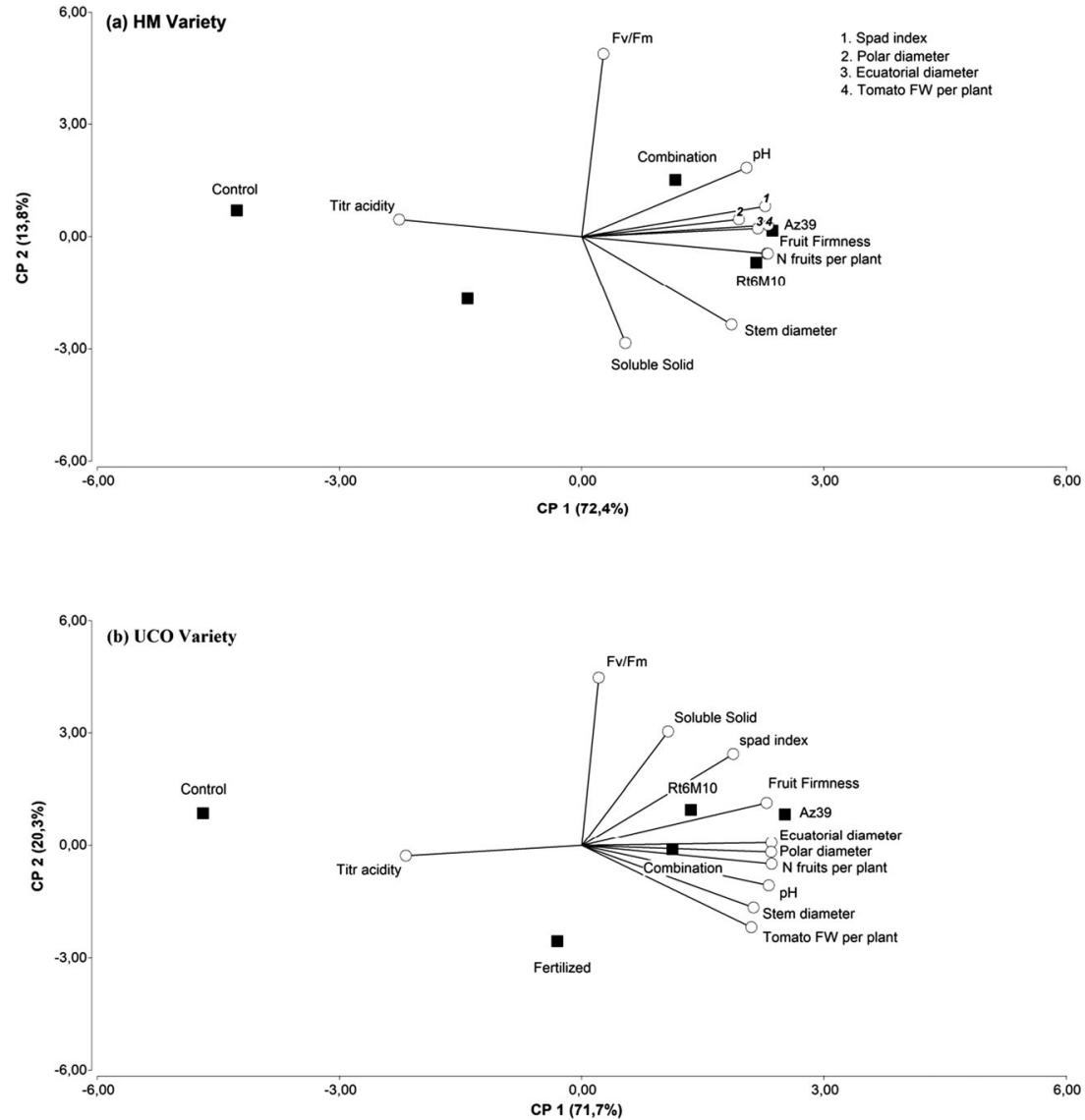
be different than the effect produced by each bacterium alone. However, other authors reported positive effects by using different consortiums in maize (Couillerot et al. 2013), cucumber (Wang et al. 2012), forage plants Mavuno grass (Sá et al. 2019), and forest species Nothofagus alpina (Martínez et al. 2018). These contradictory results with the use of combinations may be related to the correct concentration of each inoculum. Our study showed that the inoculation with Az39 and the combination equalized seedling fertilization treatment, while inoculation with Rt6M10 overtook the seedling fertilization effect. Adesemoye et al. (2009) reported similar results using PGPR and AMF. The increased biomass of seedlings inoculated with Az39 or Rt6M10 could be partly related to hormone production, $\mathrm{N}$ fixation, and $\mathrm{P}$ solubilization by PGPR (Glick 2012). A. brasilense and Rt6M10 produce different plant hormones, such as indole-3-acetic acid, abscisic acid, and gibberellins that modify the root architecture and improve the ability of plants to absorb water and transport assimilates (Bottini et al. 2004; Cohen et al. 2015; Murcia et al. 2017; Salomon et al. 2014). Also, both bacterial strains are efficient phosphate solubilizers and $\mathrm{N}$ fixers (García de Salamone et al. 2012; Salomon et al. 2014). The beneficial effect of PGPR inoculation on tomato roots and stems has also been reported by other authors in experiments carried out under field or greenhouse conditions (Kokalis-Burelle et al. 2002; Mena-Violante and Olalde-Portugal 2007; Walia et al. 2014). Our findings are in agreement with the results presented in the above studies. In fact, in our experiment, control seedlings had lower development of the root system and thus a higher SDW/RDW ratio (3.38), implying higher dry matter allocation to the seedlings shoots, as compared with the fertilized or inoculated seedlings that had SDW/RDW ratios of 2.89, 2.93, and 2.71, respectively. At this point, it is important to clarify that "true" field fertilization was not performed in this study because periodical soil analysis indicated the levels of nutrients suffice for a normal tomato crop. Transplanting tomato seedlings with an improved root system that can uptake plant nutrients and water from the soil will enhance plant establishment, growth, and yield. Additionally, inoculation increased stem diameter of the two varieties at the reproductive stage under field conditions, indicating a higher plant vigor when compared with control, similarly to what was reported by Bona et al. (2018).

In our experiments, the $\mathrm{Fv} / \mathrm{Fm}$ ratio was not influenced by PGPR inoculation, although plants coming from chemically fertilized seedlings presented lower values than the other treatments. In contrast, Cordero et al. (2018) reported that inoculation and chemical fertilization increased $\mathrm{Fv} / \mathrm{Fm}$ of tomato plants. A possible explanation of this finding might be the plant phenology at the moment of $\mathrm{Fv} / \mathrm{Fm}$ determination. In our case, Fv/Fm determination was performed in the reproductive stage, but in the majority of the works, this parameter was measured in the vegetative stage.
Interestingly, there was an increase in the chlorophyll content and photoprotective compounds as a result of Rt6M10 inoculation. The carotenoid levels were increased by inoculation and fertilization. Others works reported increased chlorophyll level with PGPR and AMF inoculation (Amirnia et al. 2019) or in chlorophyll and carotenoids levels after a PGPR treatment in potato (Dawwam et al. 2013) and Arabidopsis thaliana plants (Cohen et al. 2015). Only the Rt6M10 inoculation treatment increased photoprotective pigments, although the anthocyanin levels were similar to non-inoculated (control) plants. In accordance with Cohen et al. (2015), the increase in photoprotective compounds can lead to plant protection against oxidative stress. The enhanced chlorophyll content and, consequently, enhanced photosynthesis may provoke an increase in tomato growth and productivity.

The similar P content in the different treatments, with the exception of the combination treatment that decreased it, and the lowest $\mathrm{N}$ content in Az39 and Rt6M10 (similar to the control) could be related to the use of a soil with adequate levels of nutrients (Sá et al. 2019) and to the fact that the samples were collected in the reproductive stage when the plant allocates nutrients to form the fruits.

Another remarkable result is the improvement in yield and quality of tomato with PGPR inoculation as compared with non-inoculated (control) seedlings. In HM variety, Rt6M10 or Az39 inoculation overtook fertilization of seedlings, while the combination equaled it. In UCO variety, all inoculation treatments equalized the effect of seedling fertilization. Similar results were reported with PGPR and AMF inoculation in corn (Adesemoye et al. 2008), or with Pseudomonas sp. and Azospirillum sp. co-inoculated in paddy rice (García de Salamone et al. 2012). Ijaz et al. $(2019,2020)$ propose the use of PGPR consortia and biochar with reduced synthetic fertilization for maximizing wheat and peanut crop production as eco-friendly alternative.

On the other hand, one of the main yield goals to produce economic benefits is the production of heavier and larger fruits. We found that PGPR inoculation increased tomato FW and fruit size (equatorial and polar diameter) in both varieties. Similar results were reported using a combination of AMF and Pseudomonas (Bona et al. 2018), Bacillus licheniformis under greenhouse conditions (García et al. 2004), and a mixture of AMF and bacteria (Bona et al. 2017). An increase in fruit size is associated with the signal pathways that modify cell expansion (auxins) and sucrose synthase enzyme which have a central role in developing tomato fruits (Carrari and Fernie 2006).

The improvements in fruit quality with PGPR inoculation is known in different crops (Bona et al. 2017). However, few works reported improvements in tomato quality with the inoculation of PGPR alone. The flavor of tomato is analyzed by sensorial measurements and furthermore by total soluble solids, $\mathrm{pH}$, titrable acidity, and soluble solid /titrable acidity 
ratio (Gómez and Camelo 2002). Another important parameter in the industry is the sweetness of tomato fruit (Bona et al. 2018). The $60 \%$ of total soluble solids are represented by sugars, mainly glucose and fructose (Gómez and Camelo 2002). In UCO variety, inoculation with Rt6M10 significantly increased this parameter. In $\mathrm{HM}$ variety, the bacteria treatment did not affect the total soluble solid content, but it might be considered that inoculated plants presented bigger fruits than control plants. Bona et al. (2017) attributed the differences in sugar concentration at compounds produced by bacteria that could modulate photosynthesis and plant sugar concentration, especially by modifying the plant hormone abscisic acid (ABA). In fact, the role of ABA in promoting sugar has been reported in grape (Moreno et al. 2011; Murcia et al. 2017). In our work, bacteria inoculation did not influence $\mathrm{pH}$ of the fruits. Similar results were presented by Ordookhani et al. (2013), with Azospirillum sp., Azotobacter sp., and AMF inoculation and also by Nzanza et al. (2012), using Trichoderma harzianum and AMF seedling inoculation. However, the inoculation influenced the titrable acidity. In HM fruits, Az39 or Rt6M10 induced a reduction of this parameter as compared with non-inoculated and chemically fertilized seedlings, whereas only Az39 inoculation induced a significant reduction compared with the seedling fertilized treatment in UCO fruits.

An important aspect of industrial tomato quality is the firmness of the fruit, since the shelf life of tomato fruits depends on this parameter. Firmer fruits are desirable in order to reduce spoilage microorganisms attack (Mena-Violante and OlaldePortugal 2007). In our work, PGPR inoculation increased this parameter in both tomato varieties. This result is in agreement with Mena-Violante and Olalde-Portugal (2007), who reported an increase in tomato fruit firmness with Bacillus subtilis BEB13-bs treatment. These results might be attributed to the reduction of the polygalacturonase gene (PG) activity that is moderately correlated with the firmness of the fruit, as described by Mena-Violante et al. (2009). Finally, no significant differences were found between tomato cultivars in the majority of the studied parameters, with the exception of equatorial diameter and $\mathrm{FW}$ of fruits. This indicates that the bacterium does not distinguish between cultivars of the same species as reported by García et al. (2004).

\section{Conclusions}

Findings of this study supported the overall hypothesis that inoculation with A. brasilense Az39 or P. fluorescens Rt6M10 enhanced seedlings growth, which in turn could avoid the need of supplemental fertilization during greenhouse production. Plant growth-promoting rhizobacteria inoculation allowed producing high-quality seedlings that likely suffered less transplant stress in the field, increasing yield and quality of tomatoes. Thus, Rt6M10 and Az39 can be used as bioinoculants implying significant economic savings for production, lowering groundwater and soil pollution and contributing to sustainable agriculture. This information may be useful for nurseries that produce tomato seedlings for growers.

Acknowledgments RB, PP, and AC are career members of CONICET; MP and VL are researchers of Instituto Nacional de Tecnología Agropecuaria (INTA). The authors wish to thank INTA personal for their help during the experiments. The authors would like to thank Elisa Dichiara, Eugenia Soler, and Cecilia Alaniz for their help during the harvesting of tomato fruits, and Cecilia Chimeno, Ana Laura Viani, and Martín López-Appiolaza for their help in fruit biochemical determinations.

Funding This work was funded by Consejo Nacional de Investigaciones Científicas y Tecnológicas (CONICET, PIP 11220130100185 CO to AC) and Universidad Nacional de Cuyo (SECyT-UNCuyo to MP, PP, and AC).

\section{Compliance with Ethical Standards}

Conflict of Interest The authors declare that they have no conflict of interest.

\section{References}

Adesemoye AO, Torbert HA, Kloepper JW (2008) Enhanced plant nutrient use efficiency with PGPR and AMF in an integrated nutrient management system. Can J Microbiol 54:876-886

Adesemoye AO, Torbert HA, Kloepper JW (2009) Plant growthpromoting rhizobacteria allow reduced application rates of chemical fertilizers. Microb Ecol 58:921-929

Ahmed M, Rauf M, Mukhtar Z (2017) Excessive use of nitrogenous fertilizers: an unawareness causing serious threats to environment and human health. Environ Sci Pollut Res 24:26983-26987

Amirnia R, Ghiyasi M, Moghaddam SS, Rahimi A, Damalas CA, Heydarzadeh S (2019) Nitrogen-fixing soil bacteria plus mycorrhizal fungi improve seed yield and quality traits of lentil (Lens culinaris Medik). J Soil Sci Plant Nutr 19:592-602

Argerich CA, Smith P (2018) Asociación Tomate 2000. Programa para el aumento de la competitividad de la industria del tomate. Informe Progresos 2017-2018. Cosme A. Argerich y Patrick Smith, Ed. La Consulta, INTA EEA La Consulta. 2018. https://inta.gob.ar/ documentos/asociacion-tomate-2000-programa-de-competitividadde-la-industria-de-tomate-informe-de-progresos-2017-2018. Accessed 18 Mar 2019

Bhardwaj D, Ansari MW, Sahoo RK, Tuteja N (2014) Biofertilizers function as key player in sustainable agriculture by improving soil fertility, plant tolerance and crop productivity. Microb Cell Factories 13:66

Bona E, Cantamessa S, Massa N, Manassero P, Marsano F, Copetta A, Lingua G, D'Agostino G, Gamalero E, Berta G (2017) Arbuscular mycorrhizal fungi and plant growth-promoting pseudomonads improve yield, quality and nutritional value of tomato: a field study. Mycorrhiza 27:1-11

Bona E, Todeschini V, Cantamessa S, Cesaro P, Copetta A, Lingua G, Berta G, Massa N (2018) Combined bacterial and mycorrhizal inocula improve tomato quality at reduced fertilization. Sci Hortic 234:160-165 
Bottini R, Cassán F, Piccoli P (2004) Gibberellin production by bacteria and its involvement in plant growth promotion and yield increase. Appl Microbiol Biotechnol 65:497-503

Carrari F, Fernie AR (2006) Metabolic regulation underlying tomato fruit development. J Exp Bot 57(9):1883-1897

Cohen AC, Travaglia CN, Bottini R, Piccoli PN (2009) Participation of abscisic acid and gibberellins produced by endophytic Azospirillum in the alleviation of drought effects in maize. Botany 87:455-462

Cohen AC, Bottini R, Pontin M, Berli FJ, Moreno D, Boccanlandro H, Travaglia CN, Piccoli PN (2015) Azospirillum brasilense ameliorates the response of Arabidopsis thaliana to drought mainly via enhancement of ABA levels. Physiol Plant 153:79-90

Cordero I, Balaguer L, Rincón A, Pueyo JJ (2018) Inoculation of tomato plants with selected PGPR represents a feasible alternative to chemical fertilization under salt stress. J Plant Nutr Soil Sci 181:694-703

Couillerot O, Ramírez-Trujillo A, Walker V, von Felten A, Jansa J, Maurhofer M, Défago G, Prigent-Combaret C, Comte G, Caballero-Mellado J, Moënne-Loccoz Y (2013) Comparison of prominent Azospirillum strains in Azospirillum-PseudomonasGlomus consortia for promotion of maize growth. Appl Microbiol Biotechnol 97(10):4639-4649

Damalas CA, Eleftherohorinos IG (2011) Pesticide exposure, safety issues, and risk assessment indicators. Int J Environ Res Public Health 8:1402-1419

Dawwam GE, Elbeltagy A, Emara HM, Abbas IH, Hassan MM (2013) Beneficial effect of plant growth promoting bacteria isolated from the roots of potato plant. Ann Agric Crop Sci 58:195-201

García de Salamone IE, Funes JM, Di Salvo LP, Escobar-Ortega JS, D'Auria F, Ferrando L, Fernandez-Scavino A (2012) Inoculation of paddy rice with Azospirillum brasilense and Pseudomonas fluorescens: impact of plant genotypes on rhizosphere microbial communities and field crop production. Appl Soil Ecol 61:196-204

García JE, Maroniche G, Creus C, Suárez-Rodríguez R, Ramirez-Trujillo JA, Groppa MD (2017) In vitro PGPR properties and osmotic tolerance of different Azospirillum native strains and their effects on growth of maize under drought stress. Microbiol Res 202:21-29

García JAL, Probanza A, Ramos B, Palomino M, Mañero FJG (2004) Effect of inoculation of Bacillus licheniformis on tomato and pepper. Agronomie 24:169-176

Glick BR (2012) Plant growth-promoting bacteria: mechanisms and applications. Scientifica 2012:963401

Glick BR (2014) Bacteria with ACC deaminase can promote plant growth and help to feed the world. Microbiol Res 169:30-39

Gómez PA, Camelo AFL (2002) Calidad postcosecha de tomates almacenados en atmósferas controladas. Hortic Bras 20:38-43

Gravel V, Antoun H, Tweddell RJ (2007) Growth stimulation and fruit yield improvement of greenhouse tomato plants by inoculation with Pseudomonas putida or Trichoderma atroviride: possible role of indole acetic acid (IAA). Soil Biol Biochem 39:1968-1977

Gyaneshwar P, Kumar GN, Parekh LJ, Poole PS (2002) Role of soil microorganisms in improving P nutrition of plants. Plant Soil 245: 83-93

Ijaz M, Tahir M, Shahid M, Ul-Allah S, Sattar A, Sher A, Mahmood K, Hussain M (2019) Combined application of biochar and PGPR consortia for sustainable production of wheat under semiarid conditions with a reduced dose of synthetic fertilizer. Braz J Microbiol 50:449458

Ijaz M, Perveen S, Nawaz A, Ul-Allah S, Sattar A, Sher A et al (2020) Eco-friendly alternatives to synthetic fertilizers for maximizing peanut (Arachis hypogea L.) production under arid regions in Punjab, Pakistan. J Plant Nutr 43:762-772
Jackson ML (1973) Soil chemical analysis. Prentice Hall (India) Pvt. Ltd., New Delhi

Jewell MC, Campbell BC, Godwin ID (2010) Transgenic plants for abiotic stress resistance. In: In Transgenic crop plants. Springer, Berlin, Heidelberg, pp 67-132

Kokalis-Burelle N, Vavrina CS, Rosskopf EN, Shelby RA (2002) Field evaluation of plant growth-promoting rhizobacteria amended transplant mixes and soil solarization for tomato and pepper production in Florida. Plant Soil 238:257-266

Kokalis-Burelle N, Kloepper JW, Reddy MS (2006) Plant growthpromoting rhizobacteria as transplant amendments and their effects on indigenous rhizosphere microorganisms. Appl Soil Ecol 31:91100

Martínez OA, Encina C, Tomckowiack C, Droppelmann F, Jara R, Maldonado C, Muñoz O, García-Fraile P, Rivas R (2018) Serratia strains isolated from the rhizosphere of raulí (Nothofagus alpina) in volcanic soils harbour PGPR mechanisms and promote raulí plantlet growth. J Soil Sci Plant Nutr 18:804-819

Mena-Violante HG, Olalde-Portugal V (2007) Alteration of tomato fruit quality by root inoculation with plant growth-promoting rhizobacteria (PGPR): Bacillus subtilis BEB-13bs. Sci Hortic 113: 103-106

Mena-Violante HG, Cruz-Hernández A, Paredes-López O, Gómez-Lim MÁ, Olalde-Portugal V (2009) Fruit texture related changes and enhanced shelf-life through tomato root inoculation with Bacillus subtilis BEB-13BS. Agrociencia 43:559-567

Moreno D, Berli F, Piccoli P, Bottini R (2011) Gibberellins and abscisic acid promote carbon allocation in roots and berries of grapevines. Plant Growth Regul 30:220-228

Murcia G, Fontana A, Pontin M, Baraldi R, Bertazza G, Piccoli PN (2017) $\mathrm{ABA}$ and $\mathrm{GA}_{3}$ regulate the synthesis of primary and secondary metabolites related to alleviation from biotic and abiotic stresses in grapevine. Phytochem 135:34-52

Nelson DW, Sommers LE (1973) Determination of total nitrogen in plant material. Agron J 65:109-112

Nzanza B, Marais D, Soundy P (2012) Response of tomato (Solanum Lycopersicum L.) to nursery inoculation with Trichoderma harzianum and arbuscular mycorrhizal fungi under field conditions. Acta Agric Scand Sect B Soil Plant Sci 62:209-215

Ordookhani K, Moezi A, Khavazi K, Rejali F (2013) Effect of plant growth promoting rhizobacteria and mycorrhiza on tomato fruit quality. Acta Hortic 989:91-96

Perrig D, Boiero ML, Masciarelli OA, Penna C, Ruiz OA, Cassán FD, Luna MV (2007) Plant-growth-promoting compounds produced by two agronomically important strains of Azospirillum brasilense, and implications for inoculant formulation. Appl Microbiol Biotechnol 75:1143-1150

Piccoli P, Bottini R (2013) Terpene production by bacteria and its involvement in plant growth promotion, stress alleviation, and yield increase. In: de Bruijn FJ (Ed) Molecular Microbial Ecology of the Rhizosphere. Wiley/Blackwell. Chapter 31 pp 335-343

Rahman KM, Zhang D (2018) Effects of fertilizer broadcasting on the excessive use of inorganic fertilizers and environmental sustainability. Sustainability 10:759

Ruzzi M, Aroca R (2015) Plant growth-promoting rhizobacteria act as biostimulants in horticulture. Sci Hortic 196:124-134

Sá GCR, Carvalho CLM, Moreira A, Hungria M, Nogueira MA, Heinrichs R, Soares Filho CV (2019) Biomass yield, nitrogen accumulation and nutritive value of Mavuno grass inoculated with plant growth-promoting bacteria. Commun Soil Sci Plan 50:1931-1942

Salomon MV, Bottini R, de Souza Filho GA, Cohen AC, Moreno D, Gil M, Piccoli P (2014) Bacteria isolated from roots and rhizosphere of 
Vitis vinifera retard water losses, induce abscisic acid accumulation and synthesis of defense-related terpenes in in vitro cultured grapevine. Physiol Plant 151:359-374

Soil Survey Staff (2014) Keys to Soil Taxonomy, 12th edn. USDA National Resources Conservation Services, Washington

Walia A, Mehta P, Chauhan A, Shirkot CK (2014) Effect of Bacillus Subtilis strain CKT1 as inoculum on growth of tomato seedlings under net house conditions. Proc Natl Acad Sci India Sect B Biol Sci 84:145-155

Walker V, Couillerot O, Von Felten A, Bellvert F, Jansa J, Maurhofer M, Bally R, Moënne-Loccoz Y, Comte G (2012) Variation of secondary metabolite levels in maize seedling roots induced by inoculation with Azospirillum, Pseudomonas and Glomus consortium under field conditions. Plant Soil 356:151-163

Wang CJ, Yang W, Wang C, Gu C, Niu DD, Liu HX, Wang YP, Guo JH (2012) Induction of drought tolerance in cucumber plants by a consortium of three plant growth-promoting rhizobacterium strains. PLoS One 7:e52565

Publisher's note Springer Nature remains neutral with regard to jurisdictional claims in published maps and institutional affiliations. 